\title{
Problems with Using Evolutionary Theory in Philosophy
}

\begin{abstract}
Does science move toward truths? Are present scientific theories (approximately) true? Should we invoke truths to explain the success of science? Do our cognitive faculties track truths? Some philosophers say yes, while others say no, to these questions. Interestingly, both groups use the same scientific theory, viz., evolutionary theory, to defend their positions. I argue that it begs the question for the former group to do so because their positive answers imply that evolutionary theory is warranted, whereas it is self-defeating for the latter group to do so because their negative answers imply that evolutionary theory is unwarranted.
\end{abstract}

\section{Keywords}

Goal of Science, Success of Science, Evolutionary (Debunking) Arguments

Seungbae Park

Division of General Studies

Ulsan National Institute of Science and Technology

Republic of Korea

nature@unist.ac.kr

Acknowledgement: I thank the anonymous referees of this journal for their useful comments. This paper was completed while I was visiting Department of Philosophy, University of California - San Diego in 2015. I thank Craig Callender, the Department Chair, for his hospitality.

\section{Introduction}

Alexander Bird (2000) and Thomas Kuhn (1962/1970) rely on evolutionary theory to argue, respectively, that science moves and does not move toward truths. Emma Ruttkamp-Bloem (2013) claims that evolutionary theory goes along with her view that present theories are (approximately) true, while K. Brad Wray claims that it goes along with his view that present theories will be discarded. Stathis Psillos (1999) and Bas van Fraassen (1980) invoke evolutionary theory to give, respectively, a realist explanation and an antirealist explanation of the success of science. David Papineau (2006) capitalizes on evolutionary theory to show that our cognitive faculties track truths, while Kathleen Atkins (1996) uses it to show that they do not track truths.

Is it legitimate to argue that evolutionary theory goes hand in hand with any of the preceding positions concerning the goal of science, the epistemic status of present theories, the success of science, and the capability of our cognitive faculties? I argue that the positive philosophical positions imply that evolutionary theory is warranted, whereas the negative philosophical positions imply that it is unwarranted. It follows that relying upon evolutionary theory is question-begging for the proponents of the former positions, and self-defeating for the proponents of the latter positions.

This paper is organized as follows. In Section 2, I critically respond to Bird and Kuhn on the issue of whether science moves toward truths; in Section 3, to Ruttkamp-Bloem and Wray on the issue of whether present theories are (approximately) true; in Section 4, to Psillos and van Fraassen on the issue of whether we should invoke truths to explain why science is successful; and in Section 5, to Papineau and Atkins on the issue of whether our cognitive faculties track truths. 
We need to be clear about the structure of evolutionary theory before proceeding to criticize the various appeals to it. Its main frames are the tree of life and the principle of natural selection (Sober, 1993: 7). The tree of life depicts how present organisms are connected with past organisms. It illustrates, for example, that humans and frogs have descended from a common ancestor, viz., fish. Fish and plants have ultimately descended from single-celled organisms. Thus, single celled organisms are the ultimate common ancestor of all plants and animals on the Earth. The principle of natural selection is an assertion about how current terrestrial organisms have descended from the single-celled organisms. Natural selection occurs when the following three conditions are met. First, variations must occur. As a result of a variation, a random process, some organisms acquire a new trait. Second, the new trait must raise the fitness of organisms, i.e., it must raise the probability that the organisms survive and reproduce. Third, the new trait must be passed onto the next generation. If at least one of these three conditions is not satisfied, natural selection cannot occur (Sober, 1993: 9). Evolutionary biologists invoke both the tree of life and the principle of natural selection to explain biological phenomena. An example will be provided in the next section, where I criticize Bird's appeal to evolutionary theory.

\section{The Goal of Science}

We once believed that the sun moves around the earth. We now believe that the earth moves around the sun. We once believed that a burning object releases phlogiston. We now believe that a burning object absorbs oxygen. An interesting question arises: Are we closer to truths than we were before? Bird (2000) relies on evolutionary theory to argue that science moves toward truths, whereas Kuhn (1962/1970) relies on the same scientific theory to argue that it does not. This section aims to show that it is question-begging for Bird, and self-defeating for Kuhn, to do so.

Bird (2000: 211-113) claims that the evolution of scientific theories is analogous to that of organisms, in that science evolves toward truths just as organisms evolve toward a certain goal. To defend his view that organisms evolve toward a certain goal, he compares two models of evolutionary change: the two-species model and the one-species model. Let me explicate them.

On the two-species model, one species evolves in response to how another species evolves. In the distant past, for example, cheetahs and gazelles were all slow runners. Variations occurred, and as a result, some cheetahs and gazelles were born with the ability to run faster. Fast cheetahs could hunt down slow gazelles, but slow cheetahs could not. As a result, fast cheetahs and gazelles tended to survive while slow cheetahs and gazelles tended to die. The ability to run fast was transmitted from one generation to the next via genes. Over many generations, fast cheetahs and gazelles survived, and slow ones died, and the average speed of both species increased. Cheetahs increased their average speed because gazelles increased their average speed, and vice versa. One species constantly increases in speed, as the other species does. Therefore, there is no fixed goal toward which these two species evolve.

On the one-species model, however, a species evolves in a stable environment. In the distant past, for example, giraffes were all short, and they lived in an environment where the average height of trees did not change. A variation occurred, and as a result, some giraffes were born with long necks. Tall giraffes were more likely to survive and reproduce than short giraffes because the tall giraffes had access to leaves the short giraffes could not reach. Tall giraffes passed their phenotype to their offspring via genes. Over many generations, tall giraffes survived and short giraffes perished. The average height of giraffes increased as 
variations accumulated. It is for this reason that current giraffes are tall. Giraffes evolve toward a fixed goal. The height of giraffes would stop increasing once it reached the optimum level because going over the optimum level would come with the cost of having to increase the sizes of the heart and other parts of the body. The one-species model yields a "more accurate analogy for the development of science" (Bird, 2000: 212). Thus, science evolves toward the fixed goal, viz., truths. ${ }^{1}$

Is it justifiable for Bird to rely on the one-species model, a part of evolutionary theory, to establish his philosophical position that science converges on truths? To answer this question, we first need to take into account the distinction that Wray (2008: 323) and Moti Mizrahi (2013: 401) make. They distinguish between $\mathrm{T}_{1}$ 's being close to the truth and $\mathrm{T}_{1}$ 's being closer to the truth than $T_{2}$. They argue that even if $T_{1}$ is closer to the truth than $T_{2}, T_{1}$ might be far from the truth. Suppose Alice and Bob are in San Francisco and that Alice is a step ahead of Bob in a race to Los Angeles. Of course, Alice is closer than Bob is to Los Angeles. Alice, however, is far from Los Angeles. Analogously, a scientific theory might be completely false, even if it is closer to the truth than its rival is. So, for example, even if the oxygen theory is closer to the truth than the phlogiston theory is, it might not even be approximately true.

Wray and Mizrahi's preceding distinction indicates that Bird's position that science moves toward truths implies either that the one-species model is not even approximately true or that it is (approximately) true. Suppose that the one-species model is completely false. It would, then, be self-confuting for Bird to appeal to the one-species model, the completely false model, to justify his philosophical position that science converges on truths. To appeal to it would amount to claiming that it is completely false that science converges on truths. Suppose that the one-species model is (approximately) true. It is, then, question-begging for Bird to appeal to it to justify his position that science converges on truths. After all, his philosophical position implies that the one-species model is (approximately) true. To appeal to the one-species model to show that science moves toward truths amounts to appealing to $p$ to justify $p$, i.e., to advancing a circular argument. Therefore, it is either self-defeating or question-begging for Bird to appeal to the one-species model to defend his philosophical position. It is more charitable, I believe, to interpret Bird as advancing a circular argument rather than a self-refuting argument.

Let me now turn to Kuhn (1962/1970). For him, the development of science consists of certain stages. To speak briefly, different schools of thought compete with each other over fundamentals during the pre-paradigmatic stage. One of the schools successfully solves a puzzle. This success establishes a paradigm and normal science begins. Normal scientists dogmatically adhere to the paradigm, articulate it, and improve scientific instruments. As serious anomalies accumulate, revolutionary science begins. Revolutionary scientists question the old paradigm, and propose an alternative paradigm. As the new paradigm handles the anomalies which plagued the old paradigm, the new paradigm replaces the old, and new normal science begins. New normal science is followed by new anomalies and new revolutionary science; thus, the cycle of normal science and revolutionary science continues.

Kuhn argues that as the cycle continues, science does not move toward truths. The development of science is a process free of a goal, just as natural selection in nature is a process free of a goal. Evolutionary theory denies that organisms evolve toward a goal set by either God or nature. Complex organisms are "products of a process that moved steadily from

\footnotetext{
1 In nature, however, a species interacts with other species, and the environment changes as continents move around. Thus, the one-species model has no application to nature.
} 
primitive beginnings but toward no goal" (Kuhn, 1962/1970: 172). Similarly, the alternations between normal science and revolutionary science occur without a goal:

And the entire process may have occurred, as we now suppose biological evolution did, without benefit of a set goal, a permanent fixed scientific truth, of which each stage in the development of scientific knowledge is a better exemplar. (Kuhn, 1962/1970: 172-173)

Thus, it is wrong to think that the kinetic paradigm is closer to the truth than the caloric paradigm, or that the Einsteinian paradigm is closer to the truth than the Newtonian paradigm. The analogy between the evolution of organisms and the evolution of scientific ideas is "very nearly perfect" (Kuhn, 1962/1970: 172).

What should we make of Kuhn's contention that evolutionary theory dovetails with his account of the development of science? If his account of the development of science is true, present theories, including evolutionary theory, are not closer to truths than their predecessors. It follows that evolutionary theory is not closer to the truth than its predecessors and that evolutionary theory is just as false as its predecessors. Given that Kuhn's account of the development of science goes hand in hand with evolutionary theory, a false scientific theory, it is also false. Note that the starting and ending point of this reasoning are, respectively, that Kuhn's account is true and false, i.e., that if his account is true, it is false.

In addition, if Kuhn's account of the development of science is true, evolutionary theory would also be true because evolutionary theory goes hand in hand with the true account of the development of science. If evolutionary theory is true, however, then other scientific theories, such as the kinetic theory of heat and the special theory of relativity, are also true, given that the sets of evidence for the other scientific theories are as powerful as that for evolutionary theory. Since evolutionary theory and the other scientific theories are true, it is false that they are not closer to truths than their predecessors, i.e., Kuhn's account of the development of science is false. Note again that the starting and ending point of this reasoning are, respectively, that Kuhn's account is true and false.

Kuhn might reply that his account of the development of science does not apply to evolutionary theory, although it does apply to other scientific theories, such as the kinetic theory of heat and the special theory of relativity. In other words, he might say that evolutionary theory is true, or closer to the truth than its predecessors, but other scientific theories are not closer to truths than their predecessors. So it is legitimate to appeal to evolutionary theory to argue that the other scientific theories are not closer to the truths than their predecessors.

The preceding reply, however, is problematic. It is not clear on what grounds we can believe that evolutionary theory is true, while not believing that the other scientific theories are true. We believe that evolutionary theory is true on the grounds that it explains biological phenomena. However, the kinetic theory of heat explains heat phenomena, and the special theory of relativity explains the behaviors of fast-moving objects. To put it differently, there is no relevant evidential difference between evolutionary theory and the other scientific theories. So if we believe that evolutionary theory is true, we should also believe that the kinetic theory of heat and the special theory of relativity are true.

In sum, it is self-confuting for Kuhn to ground his account of the development of science on evolutionary theory.

\section{The Epistemic Status of Present Theories}


Are present theories, such as the oxygen theory of combustion, the kinetic theory of heat, and the special theory of relativity, (approximately) true? Ruttkamp-Bloem (2013) claims that evolutionary theory goes well with her view that present theories have true theoretical constituents. By contrast, Wray (2011) claims that evolutionary theory goes well with his view that present theories will be discarded. This section aims to show that it is questionbegging for Ruttkamp-Bloem, and self-defeating for Wray, to claim so.

Like other philosophers, Ruttkamp-Bloem (2013) compares the evolution of scientific theories to that of organisms. Scientific theories adapt to new experimental results and background knowledge, just as organisms adapt to their new environments:

Thus, in this context what is most seductive about the notion of evolution are (1) the idea of never-ending infinitesimal adaptation, and the result of such adaptation being the generation of more complex - more nuanced, refined - forms of whatever is doing the adapting - scientific theories in this case; (Ruttkamp-Bloem, 2013: 207)

In other words, scientific theories are revised in the light of new empirical data and background theories, just as organisms change their morphologies in response to changes in their environments. Ruttkamp-Bloem uses this analogy to defend a position that she calls naturalized realism. Naturalized realism claims, among other things, that "we can justifiably believe those constituents of theories that have been revised to various degrees or that have remained unrevised in the face of change at the empirical level" (Ruttkamp-Bloem, 2013: 209).

Let me call adapted theories the theories which have been revised in the light of new experimental data and background theories, or the ones which have theoretical constituents that are stable despite the change of experimental data and background theories. Are adapted theories (approximately) true or completely false? Ruttkamp-Bloem does not explicitly say that they are (approximately) true, but it is more reasonable to interpret naturalized realism as asserting that they are. After all, if naturalized realism asserts that they were completely false, 'naturalized realism' would clearly be a misnomer, and 'naturalized antirealism' would be the right nomenclature.

Is it legitimate to appeal to the analogy between the revision of scientific theories and the adaptation of biological organisms to defend naturalized realism? My answer is that making such an appeal is circular. The appeal to the analogy presupposes that evolutionary theory has true constituents, i.e., it is (approximately) true. After all, if evolutionary theory is utterly false, the analogy would be inadequate to justify any philosophical position. Naturalized realism, however, asserts that adapted theories, including evolutionary theory, are (approximately) true. Note that naturalized realism implies that evolutionary theory is (approximately) true. Thus, using evolutionary theory to defend naturalized realism amounts to appealing to naturalized realism to defend naturalized realism.

Let me now turn to Wray (2011). He claims that Kuhn's “evolutionary perspective on science is an important resource for developing an adequate epistemology of science" (Wray, 2011: 8). He develops Kuhn's analogy between biological and scientific evolutions, saying that old scientific concepts are discarded with the advent of new scientific theories, just as old morphologies are discarded when a species becomes a new species in nature. Waste and "destruction are thus as prevalent in the biological world as they appear to be in the scientific world" (Wray, 2011: 136). Wray's contention that waste and destruction are prevalent in the scientific world, just as they are in the biological world implies that present theories will be discarded as past theories were. 
It is useful to note in this context that Wray endorses Stanford's (2006) pessimistic induction, which holds that "the history of scientific inquiry itself offers a straightforward rationale for thinking that there typically are alternatives to our best theories" (Stanford, 2006: 19). Wray endorses Stanford's pessimistic induction as follows:

Consequently, it seems likely that future developments in a field will reveal additional competing theories that are also able to account for the data, theories, though, that are now unconceived alternatives. (Wray, 2010: 371)

If Stanford's pessimistic induction is correct, present theories will be replaced by future theories which present scientists cannot conceive of, just as past theories were replaced by present theories which the past scientists could not conceive of. Future theories will differ radically from present theories in their claims about unobservables, just as present theories differ radically from past theories in their claims about unobservables. It follows that both past and present theories are not even approximately true.

What are we to make of Wray's contention that waste and destruction are as prevalent in the scientific world as they are in the biological world? If the pessimistic induction is correct, present theories, including evolutionary theory, are false. If evolutionary theory is false, however, it is false that waste and destruction are prevalent in the biological world. Since the pessimistic induction goes hand in hand with the false view of the biological world, it is incorrect. Note that the starting and ending point of this reasoning are, respectively, that the pessimistic induction is correct and incorrect.

If the pessimistic induction is correct, waste and destruction are prevalent in the scientific world. Since the scientific world is as evolutionary says it is, evolutionary theory is true. If, however, we can believe that evolutionary theory is true, we can also believe that other present theories, such as the kinetic theory of heat and the special theory of relativity are true, given that the sets of evidence for them are as powerful as that for evolutionary theory. If we can believe that the present theories are true, however, the pessimistic induction is incorrect. Note again that the starting and ending point of this reasoning are, respectively, that the pessimistic induction is correct and incorrect.

In sum, it is self-undermining for Wray to say that evolutionary theory meshes well with the pessimistic induction.

\section{The Success of Science}

Science has enabled us to produce genetically modified organisms, explain why a solar eclipse occurs, and predict when Hawaii will bump into the Kamchatka peninsula. Why is science successful? Van Fraassen (1980) and Wray $(2007,2010)$ invoke evolutionary theory to provide an antirealist explanation of the success of science, whereas Psillos (1999) invokes the same scientific theory to provide a realist explanation of the success of science. This section aims to show that it is question-begging for Psillos, and self-defeating for van Fraassen and Wray, to do so. Let me begin with van Fraassen and Wray's antirealist explanation, since Psillos's realist explanation is a response to it.

Van Fraassen claims that science is successful because only "the successful theories survive - the ones which in fact latched on to actual regularities in nature" (1980: 40). Wray endorses van Fraassen's explanation, saying that "van Fraassen's selectionist explanation is superior to the realists" explanation" (2007: 85) and that the "selection mechanism operative in science, like natural selection in the biological world, is essentially an eliminative process, getting rid of the least fit alternatives" (2010: 376). 
Van Fraassen and Wray's evolutionary explanation of the success of science is advanced as an alternative to Putnam's (1975: 73) realist explanation, which says that science is successful because successful theories are (approximately) true. The success of science would be a miracle if successful theories are false. According to van Fraassen and Wray, the success of science can be explained not in terms of truth, but rather in terms of the survival of successful theories and the death of unsuccessful theories. So we need not believe that successful theories are true.

What are we to make of van Fraassen and Wray's evolutionary explanation of the success of science? If it is warranted, the success of present theories can be explained without invoking their truths, and hence present theories, including evolutionary theory, are unwarranted. If evolutionary theory is unwarranted, however, van Fraassen and Wray's explanation of the success of science is also unwarranted because it relies upon that unwarranted scientific theory. Note that the starting and ending point of this reasoning are, respectively, that van Fraassen and Wray's evolutionary explanation is warranted and unwarranted.

If van Fraassen and Wray's explanation of the success of science is warranted, evolutionary theory is also warranted. After all, how can an explanation be warranted when its presupposition is unwarranted? If, however, evolutionary theory is warranted, other present theories, such as the kinetic theory of heat and the special theory of relativity, are also warranted, given that they enjoy more or less the same epistemic status as evolutionary theory. This corollary, however, goes contrary to the antirealist spirit of van Fraassen and Wray's evolutionary explanation, which holds that present theories are unwarranted. So their explanation is unwarranted. Note again that the starting and ending point of this reasoning are, respectively, that van Fraassen and Wray's evolutionary explanation is warranted and unwarranted.

In sum, it is self-refuting for antirealists to invoke evolutionary theory to give an antirealist explanation of the success of science, as Seungbae Park (2014: 268-269) observes.

There is a further problem with van Fraassen's use of evolutionary theory. Evolutionary theory claims that organisms do not evolve toward a fixed goal, but constructive empiricism claims that science "aims to give us theories which are empirically adequate theories" (van Fraassen, 1980: 12). These claims conflict with each other. So constructive empiricists have the burden of reconciling these conflicting claims, before they avail themselves of evolutionary theory for their philosophical purposes.

Let me now turn to Psillos (1999: 96-97). He argues that van Fraassen's evolutionary explanation is compatible with the realist explanation that science is successful because successful theories are true. Furthermore, he continues, the realist explanation is better than van Fraassen's evolutionary explanation because the former is genotypic while the latter is phenotypic:

Notice here that the realist explanation is compatible with van Fraassen's Darwinian account. Yet, the realist's is arguably preferable, because it is deeper. It does not stay on the surface that is, it does not just posit a selection mechanism which lets through only empirically successful theories. It rather tells a story about the deeper common traits in virtue of which the selected theories are empirically successful. (Psillos, 1999: 96)

For example, why do current mice run fast from cats? The phenotypic explanation holds that current mice run fast from cats because fast mice survived, while slow mice died. The genotypic explanation adds that fast mice had certain genes that predisposed them to run fast, while slow mice did not. Analogously, the phenotypic explanation of the success of science 
holds that science is successful because successful theories survive, while unsuccessful theories die. The genotypic explanation adds that successful theories are true and that unsuccessful ones are false. The genotypic explanation dovetails with evolutionary theory more seamlessly than the phenotypic explanation does. Hence, the former is better than the latter.

What should we make of Psillos's appeal to evolutionary theory to defend his realist explanation of the success of science? His genotypic explanation asserts that successful theories, including evolutionary theory, are true. So appealing to evolutionary theory to defend the realist explanation amounts to appealing to $p$ to justify $p$. In addition, Psillos's contention that his genotypic explanation is better than van Fraassen's phenotypic explanation because the former coheres with evolutionary theory more tightly than the latter does amounts to the contention that $p$ is better than $q$ because $p$ coheres with $p$ more tightly than $q$ does. Such an argument is circular.

There is a further problem, I must add, with Psillos's use of evolutionary theory. Evolutionary theory clashes with realism. Realism asserts that science moves toward truths, but evolutionary theory asserts that organisms do not evolve toward a fixed goal. Realists have the burden of reconciling these conflicting claims, before they avail themselves of evolutionary theory for their philosophical purposes.

\section{The Capability of Our Cognitive Faculties}

Our cognitive faculties enable us to perceive and conceptualize the world. They produce scientific beliefs, such as the beliefs that the earth is round and that water is $\mathrm{H}_{2} \mathrm{O}$. Are such beliefs true or merely useful? Some philosophers deploy evolutionary theory to argue that our cognitive faculties track truths, while others deploy it to argue that they do not. This section aims to show that it is question-begging for the former group, and self-defeating for the latter group, to do so.

Papineau (2006) uses evolutionary theory to argue that our cognitive faculties are reliable. Natural selection enhanced our cognitive faculties so that they produce beliefs that are not only useful but also true. In general, true beliefs are useful means to achieve the ends of longevity and fecundity. A gene that predisposes organisms to pursue true beliefs is beneficial for survival and reproduction. Papineau says that "any gene that made them desire truth in itself would have been strongly favored by natural selection" (2006: 74).

Arguments which rely on evolutionary theory to defend the reliability of our cognitive faculties are called evolutionary arguments, as opposed to evolutionary debunking arguments, in the literature. Evolutionary arguments range not only over scientific beliefs but also over moral, religious, and common sense beliefs. The general scheme of evolutionary arguments is as follows:

1. Animals that can successfully interact with the world have a higher chance of passing on their genes than animals that do not successfully interact with the world.

2. Beliefs about the world that accurately track those states of affairs in the world are, on the whole, better guides to action than are false beliefs.

3. Therefore, natural selection will favor those animals with reliable sensory and belief formation systems insofar as those sensory systems and beliefs have a bearing on the animals' fitness. (De Cruz and De Smedt, 2012: 417)

If natural selection favored cognitive faculties that tracked truths, the beliefs produced by our cognitive faculties would mostly be true. Thus, evolutionary theory supports optimism that 
scientific beliefs, moral beliefs, religious beliefs, and common sense beliefs are mostly true. Note that evolutionary arguments presuppose that evolutionary theory is true.

In my view, it is circular for proponents of evolutionary arguments to say that since evolutionary theory suggests that our cognitive faculties are reliable, our cognitive faculties are reliable. Their conclusion that our cognitive faculties track truths implies that evolutionary theory is warranted. Thus, to appeal to evolutionary theory to establish the reliability of our cognitive faculties amounts to appealing to $p$ to justify $p$. Such an argument is convincing only to those who previously had the belief that our cognitive faculties are reliable.

Let me now turn to Akins (1996). She argues that our cognitive faculties produce merely useful beliefs. The sensory system, for example, generates perceptual information which the motor system can use so that the organism survives and reproduces. The perceptual beliefs need not be true to be useful to the motor system:

For every evolved system, there will be a symbiotic relationship between the information gathering of the sensory system and the informational needs of the motor system-and the elegant solutions that evolution eventually selects need not involve any straightforward (to our eyes) "veridical" encoding of sensory information. (Akins, 1996: 353)

The evolutionary consideration that our cognitive faculties are not truth-oriented but fitnessoriented undermines not only scientific beliefs but also moral, religious, and common sense beliefs. Such arguments are called evolutionary debunking arguments in the literature. The general scheme of these debunking arguments is as follows:

1. We believe that $p$, because we have an intuition that $\mathrm{p}$, and there is an evolutionary explanation of our intuition that $p$.

2. Evolution is not a truth-tracking process.

3. Therefore, we are not justified in believing that $p$. (De Cruz and De Smedt, 2012: 419)

We are not justified in holding scientific, moral, religious, or common sense beliefs, if our cognitive faculties are designed not to produce accurate representations of the world but merely to raise the chance that we survive and reproduce. Note that evolutionary debunking arguments presuppose that evolutionary theory is true.

What should we make of evolutionary debunking arguments? If they are correct, our cognitive faculties do not track truths, and hence scientific beliefs, including evolutionary theory, are unwarranted. If evolutionary theory is unwarranted, however, evolutionary debunking arguments are incorrect because they are built upon that unwarranted theory. Note that the starting and ending point of this reasoning are, respectively, that evolutionary debunking arguments are correct and incorrect.

If evolutionary debunking arguments are correct, evolutionary theory is warranted. After all, evolutionary debunking arguments are built upon evolutionary theory. If evolutionary theory is warranted, however, other present theories whose epistemic status is as high as that of evolutionary theory are also warranted. If they are warranted, the evolutionary debunking arguments, which say that they are unwarranted, is incorrect. Note again that the starting and ending point of this reasoning are, respectively, that evolutionary debunking arguments are correct and incorrect.

In sum, it is self-undercutting for proponents of evolutionary debunking arguments to appeal to evolutionary theory to show that our cognitive faculties do not track truths. 


\section{Conclusion}

Philosophers employ evolutionary theory to defend the positive and the negative positions concerning the issues of whether science moves toward truths, whether successful present theories are (approximately) true, whether truths should be invoked to explain the success of science, and whether our cognitive faculties track truths. When they rely on evolutionary theory, the defenders of the positive positions advance circular arguments, while those of the negative positions advance self-defeating arguments. A moral is that when evolutionary theory is at stake, philosophers should argue for their philosophical positions without appealing to it.

That does not mean, however, that circular arguments and self-refuting arguments are equally problematic. In my view, circular arguments are less problematic than selfundermining arguments. While circular arguments are merely unconvincing to those who have already rejected their conclusions, self-confuting arguments involve contradictions. Therefore, while the former has a chance to fly, the latter does not.

\section{References}

Atkins, Kathleen (1996). "Of Sensory Systems and the 'Aboutness' of Mental States", Journal of Philosophy 93 (3): 337-372.

Bird, Alexander (2000). Thomas Kuhn. Princeton: Princeton University Press.

De Cruz, Helen and Johan De Smedt (2012). "Evolved Cognitive Biases and the Epistemic Status of Scientific Beliefs", Philosophical Studies 157 (3): 411-429.

Kuhn, Thomas (1962/1970). The Structure of Scientific Revolutions. Chicago: University of Chicago Press.

Mizrahi, Moti (2013). "The Argument from Underconsideration and Relative Realism", International Studies in the Philosophy of Science 27 (4): 393-407.

Papineau, David (2006). “The Evolution of Knowledge”, In David Papineau (ed.), The Roots of Reason: Philosophical Essays on Rationality, Evolution, and Probability. (pp. 39-82). Oxford: Oxford University Press.

Park, Seungbae (2014). "On the Evolutionary Defense of Scientific Antirealism", Axiomathes 24 (2): 263-273.

Psillos, Stathis (1999). Scientific Realism: How Science Tracks Truth. New York: Routledge.

Putnam, Hilary (1975). Mathematics, Matter and Method (Philosophical Papers, vo. 1), Cambridge: Cambridge University Press.

Ruttkamp-Bloem, Emma (2013). "Re-enchanting Realism in Debate with Kyle Stanford", Journal for General Philosophy of Science 44 (1): 201-224.

Sober, Elliott (1993). Philosophy of Biology. Boulder, CO: Westview Press. 
Stanford, P. Kyle (2006). Exceeding Our Grasp: Science, History, and the Problem of Unconceived Alternatives. Oxford: Oxford University Press.

van Fraassen, Bas (1980). The Scientific Image. Oxford: Oxford University Press.

Wray, K. Brad (2007). "A Selectionist Explanation for the Success and Failures of Science", Erkenntnis 67 (1): 81-89.

(2008). "The Argument from Underconsideration as Grounds for Anti-Realism: A Defence", International Studies in the Philosophy of Science 22 (3): 317-326.

--------- (2010). “Selection and Predictive Success”, Erkenntnis 72 (3): 365-377.

-------- (2011). Kuhn's Evolutionary Social Epistemology. Cambridge: Cambridge University Press. 